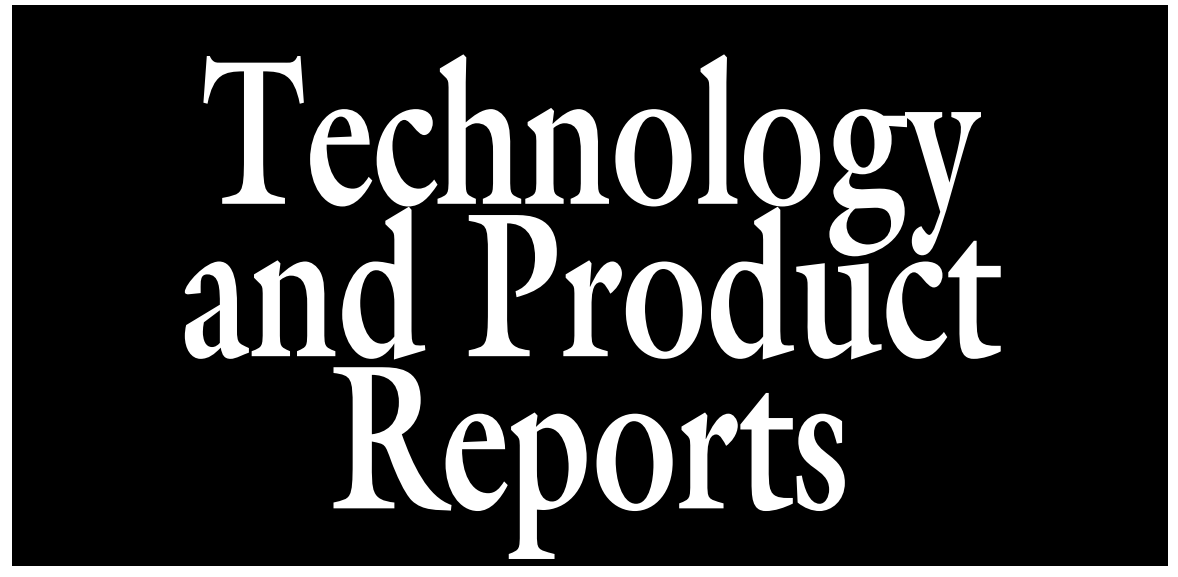

\title{
Specialty Crop Growers' Perspectives on Adopting New Technologies
}

\author{
Shannon Caplan ${ }^{1,4}$, Bryan Tilt ${ }^{1}$, Gwen Hoheisel ${ }^{2}$, \\ and Tara A. Baugher ${ }^{3}$
}

\begin{abstract}
AdDitional INDEX wORDs. automation, Cooperative Extension Service, fruit quality, labor efficiency, nursery production, Specialty Crops Research Initiative

SUMMARY. Increasing labor costs and changes in labor forces have prompted an increased demand for automation in specialty crop production. Implementation of technological innovations in the agricultural sector tends to be slow, thus this study investigated motivations and perceptions of technology. Using qualitative interviewing and analysis, this study used a diffusion of innovations framework to gain insight into what channels of communications impacted planned adoption rates and what aspects of technology influence the decision-making process. Interview participants emphasized the inevitability of implementing new technologies while considering the capital investment of more complex technology, changes in labor management to integrate technology, applicability of technology to current practices, and trust in technology designers.
\end{abstract}

$\mathrm{T}$ There is a need for increased automation in specialty crop production in the United States, especially in response to increasing labor costs and the potential for labor shortages. Technological innovations are being developed to address such concerns, as well as providing tools to acquire and disseminate data in new forms. The effectiveness of such

This research was supported by the U.S. Department of Agriculture under the Specialty Crop Research Initiative, award number 2008-51180-04876.

We acknowledge the valuable contributions of K. Lewis, C. Seavert, J. Owen, K. Ellis, S. Singh, M. Bergerman, and the entire "Comprehensive Automation for Specialty Crops" research team and all of our interview participants.

${ }^{1}$ Department of Anthropology, Oregon State University, 238 Waldo Hall, Corvallis, OR 97331

${ }^{2}$ Washington State University, Benton County, 1121 Dudley Avenue, Prosser, WA 99350

${ }^{3}$ The Pennsylvania State University, Adams County, 670 Old Harrisburg Road, Gettysburg, PA 17325

${ }^{4}$ Corresponding author. E-mail: caplans@onid.orst.edu. technology relies, in part, on acceptance and implementation by industry practitioners. This project supplements efforts of a 4-year, multidisciplinary U.S. Department of Agriculture Specialty Crop Research Initiative project focused on research, development, and transfer of labor saving and crop intelligence technologies [Comprehensive Automation for Specialty Crops (CASC)].

The implementation of new technologies in the agricultural sector tends to be slow, and there is a need to increase the speed of adoption of automation and sensor technologies before they become outdated (Alston et al., 1995; Kitchen, 2008; Koundouri et al., 2006). Prior investigations indicate that technology adoption is inhibited by cost, perceived risk, and equipment complexity while conversely adoption is increased by perceived economic benefits, the potential to decrease production risks, and ease of use (Adrian et al., 2005; Koundouri et al., 2006; Reichardt and Jürgens, 2009; Sassenrath et al., 2008). Early adopters tend to have greater knowledge about the benefits of a technology (Llewellyn, 2007), whereas late adopters waited to obtain information from early adopters (Lamb et al., 2008).

A prior case study showed that on-farm trials increased adoption of a new technology in tree fruit. Interviews of 11 Pennsylvania producers and orchard managers who had cooperated in commercial-scale research with a mechanical blossom thinner on a total of 154 acres showed economic benefits and ease of use (Baugher et al., 2010). All case study cooperators reported that mechanical thinning impacted orchard management by making crop load management more efficient and by reducing follow-up hand thinning time. Eighty percent of the growers noted fruit from thinned trees were larger and had increased market value. Cooperators also reported that machine adjustments for variable levels of thinning could be easily achieved. Seven of the 11 cooperators have since adopted the mechanical thinning technology.

A survey was conducted the first year of the CASC project to assess factors that might influence the adoption of automation and crop intelligence technologies under investigation (Ellis et al., 2010). Over 100 specialty crop producers were surveyed at tree fruit conventions held in the midAtlantic U.S. and Pacific northwestern U.S. fruit growing regions. Most responses were consistent across the two regions, with on-farm trials showing increased efficiency and economic analyses presenting evidence of increased returns being associated with a greater likelihood of technology adoption. Differences in responses from the two regions included a greater northwestern U.S. emphasis on the need for sensors to determine irrigation scheduling and a willingness of Pacific northwestern U.S. producers to pay more for a

\begin{tabular}{llll}
\hline $\begin{array}{l}\text { Units } \\
\begin{array}{l}\text { To convert U.S. to SI, } \\
\text { multiply by }\end{array}\end{array}$ & U.S. unit & SI unit & $\begin{array}{l}\text { To convert SI to U.S., } \\
\text { multiply by }\end{array}$ \\
\hline 1.6093 & mile(s) & $\mathrm{km}$ & 0.6214
\end{tabular}


harvest-assist technology that was reliable and efficient.

The goal of this project was to gain deeper insight into the factors that influence the adoption of new technologies or practices. The study draws upon previous research in a field called

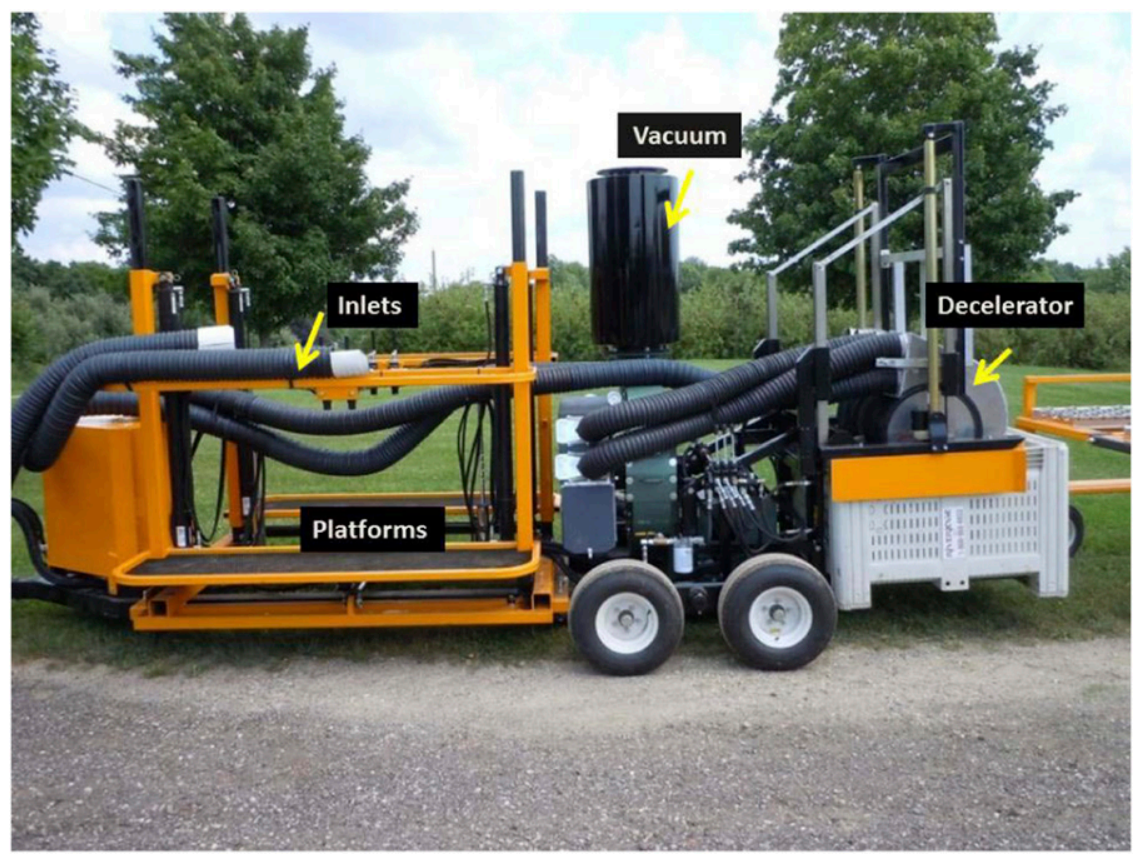

Fig. 1. Harvest-assist system designed by DBR Conveyor Concepts (Conklin, MI). Harvest employees pick fruit from platforms that can be adjusted to various tree heights and widths and place fruit in one of four inlets to a vacuum system. Vacuum tubes efficiently transport fruit, and a decelerator gently places apples in a bin.

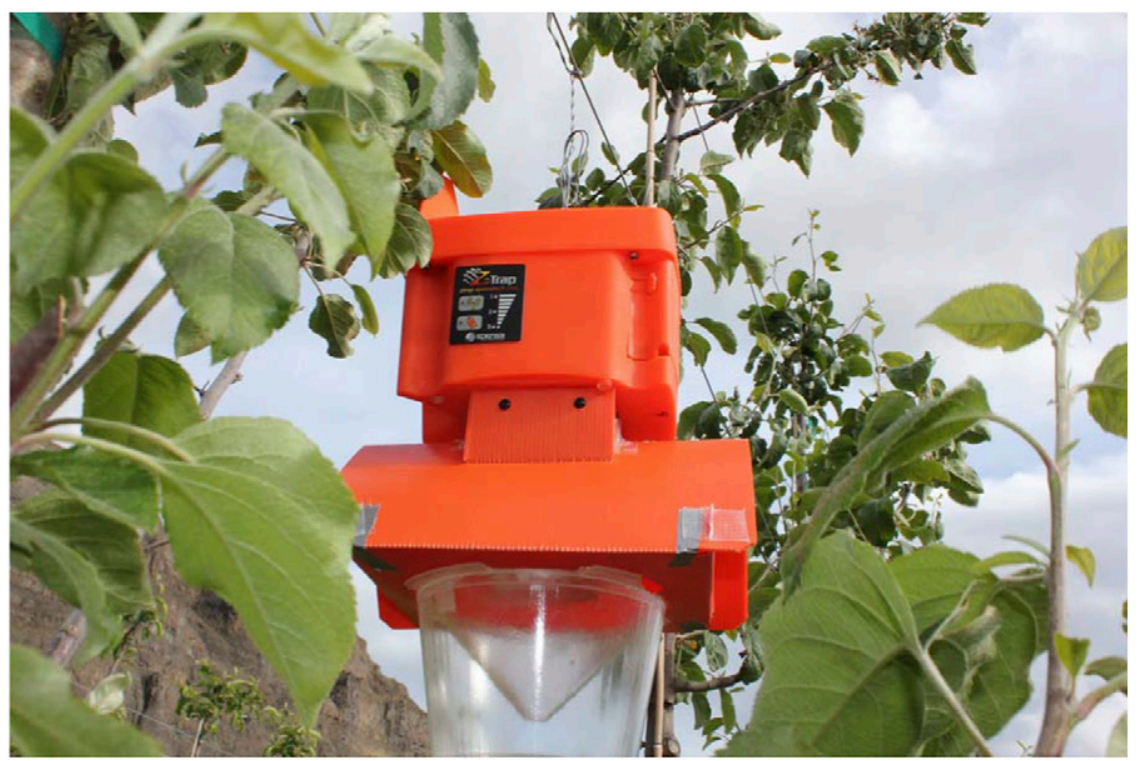

Fig. 2. Electronic insect trap designed by Spensa Technologies (West Lafayette, IN). Like current traps, it uses pheromones to attract target insects. Its novelties are a high-voltage coil to stun insects entering the trap, bio-impedance sensors to count insects automatically as they fall into the trap, a wireless connection to send pest information directly to a server on the farm, and handheld, web-based software to manage the entire system. implementation of new technologies among growers in Pennsylvania, WA, and Oregon. This article will discuss findings regarding 1) benefits and challenges (from the growers' perspectives) of adopting new technologies (harvest-assist technology and electronic insect traps) in the fruit tree sector and 2) benefits and challenges (from the growers' perspectives) of adopting an "on-the-fly" counter and caliper in the ornamental and fruit tree nursery sector.

The harvest-assist machine for the fruit tree sector was developed by DBR Conveyor Concepts (Conklin, $\mathrm{MI}$ ) and consists of a platform for workers to deposit fruit into large vacuum tubes for gentle transport to a bin (Fig. 1). The electronic insect trap, or Z-trap (Spensa Technologies, West Lafayette, IN), uses a pheromone lure to attract insects into the trap where they hit a charged coil and are counted (Fig. 2). Insect counts are transmitted to a base station and viewed by the user on their computer. The digital counter and caliper for the nursery sector consist of 1 ) a sensor to detect each tree as it passes when attached to an all-terrain vehicle (ATV) or tractor, 2) a low-cost global position system to record location, and 3 ) a graphic user interface to control the machines and view results (Fig. 3).

Although the counter and caliper technology was designed for nursery use, we also asked fruit tree growers about the technology to explore how technology may diffuse or be repurposed across industries. Finally, we will discuss implications of our findings and offer suggestions for future research.

\section{Materials and methods}

During this phase of the project, a purposive sample of 24 growers (i.e., directed sampling to ensure representation among all cohorts) was recruited and interviewed as described in Table 1.

Semistructured interviews were conducted with these participants on a range of topics related to the adoption of technologies, to understand 1) their perceptions of what attributes these technologies should have; 2) what barriers to adoption they may experience; and 3 ) how the system could add value to their product. Interviews were conducted at participants' places of business, places of residence, or, in a few cases, over the phone due to scheduling/traveling 


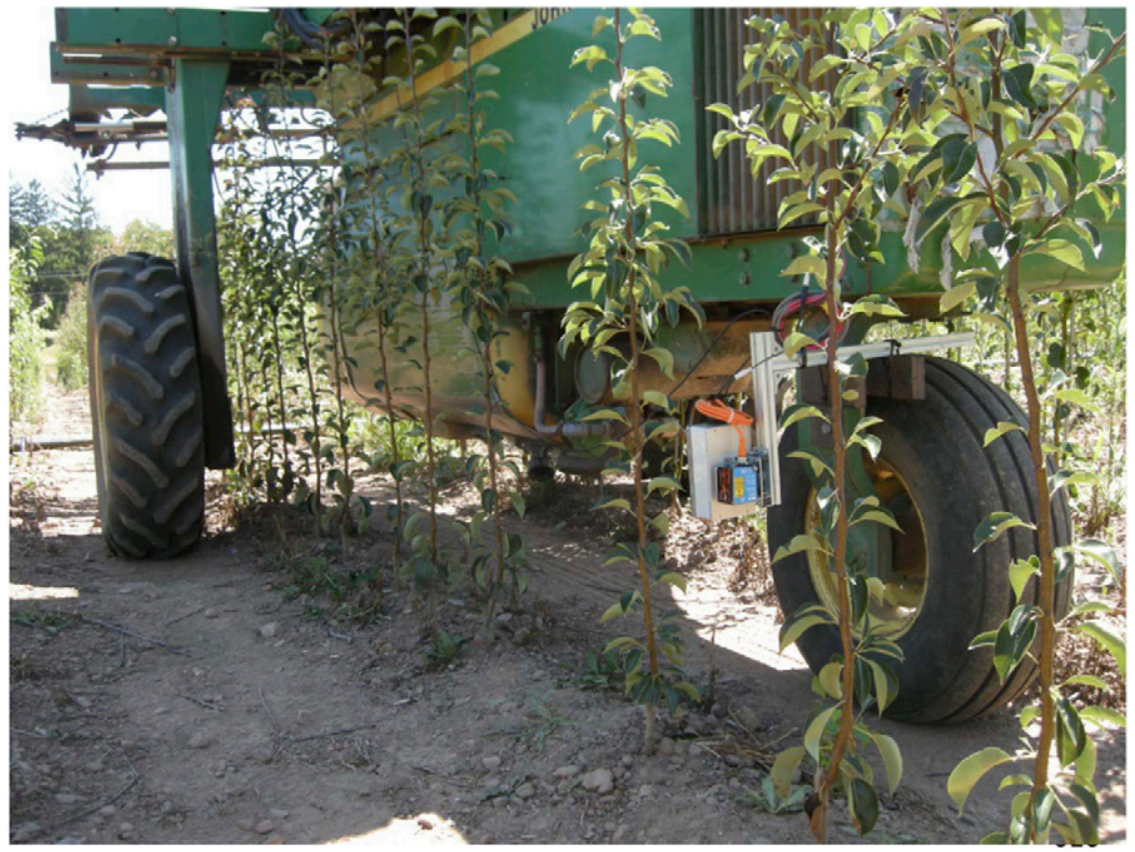

Fig. 3. On-the-Fly counter and caliper. Sensors were designed by Carnegie Mellon University (Pittsburgh, PA) engineers to count trees in a nursery field and to determine the diameter of the trunks. The sensor shown here is used to take an inventory of trees before harvest.

Table 1. A purposive sample of 24 growers, representative of two specialty crop sectors and three farm sizes, were recruited and interviewed.

\begin{tabular}{lccc}
\hline \multicolumn{4}{c}{ Fruit tree grower participants } \\
\hline & Pennsylvania & Washington \\
\hline Small operations $(<200$ acres) & 3 & 3 & $n=6$ \\
Medium operations $(200-400$ acres $)$ & 3 & 2 & $n=5$ \\
Large operations $(>400$ acres) & 3 & 3 & $n=6$ \\
& $n=9$ & $n=8$ & $n=17$
\end{tabular}

Ornamental and fruit tree nursery grower participants

\begin{tabular}{lccc}
\hline & Washington & Oregon & \\
Non-stratified & 3 & 4 & $n=7$ \\
\hline
\end{tabular}

${ }^{2} 1$ acre $=0.4047$ ha

constraints. Interviews conducted in Pennsylvania and Washington included extension educators familiar with the technologies. Several participants categorized in the fruit tree sector are involved in diversified business models, including production growing and fruit processing/distribution or production growing and nursery growing. These participants were asked to constrain their answers to the production part of their businesses.

All interviews were digitally recorded and transcribed verbatim. Data from the interviews were analyzed in the NVivo qualitative analysis software package (Gibbs, 2002), using theme analysis and content analysis techniques (Bernard, 2005; Hammersley and Atkinson, 1995). This body of qualitative data allows us to gain a better on-the-ground understanding of how growers may experience these new technologies.

Qualitative methods provide access to richness and depth without inherently requiring an extensive or statistically significant sample size. In semistructured interviews, questions are designed to allow the participant to explain in detail topical issues without being guided or limited by the interviewer (Bernard, 2005; Miles and Huberman, 1994). An interview guide of open-ended questions is used, but additional questions may be added based on participant responses. Accordingly, responses can be filled with nuance unanticipated by the researcher. Rather than focusing solely on frequency of a certain idea, qualitative data also consider the breadth of responses. For example, we asked participants what benefits they would receive from implementing a specific technology. Participants listed a wide variety, some in common. Even when thematically similar, the surrounding explanation varied at times. Ideas that had not occurred to the research team can emerge from semistructured interviews and inform future research.

CONCEPTUAL FRAMEWORK. This phase of the research draws on literature in rural sociology and anthropology on "diffusion of innovations," which seeks to understand what factors influence the adoption of new technologies or practices. According to this body of research, three main dimensions influence the adoption of technology: the characteristics of the technology itself, the characteristics of users, and the environmental context (Rogers, 2003; Wejnert, 2002). Our interview protocol reflects these three main dimensions of influence.

Under a diffusion of innovations model, innovations considered to have greater relative advantage, compatibility with current practices, trialability, observability, and less complexity will be adopted more rapidly than other innovations (Rogers, 2003). Trialability is how much an innovation can be experimented with on a limited basis, such as at an exposition (Rogers, 2003). Observability is the visibility of results of an innovation to others (Rogers, 2003). Increased trialability and observability increase the likelihood of adoption, in part due to peer discussion of innovations. Furthermore, innovations are more likely to be adopted and diffuse more rapidly if adopters can customize or re-invent the technology to fit their specific needs (Rogers, 2003), rather than needing to change their current practices to suit the technology. Such behaviors could be correlated to risk aversion; however, this project was not designed to directly explore or assess such behavioral tendencies.

Communication similarly influences the speed of adoption of innovations. Rather than rely solely on objective evidence, adopters will more likely rely on subjective evaluation from individuals who have adopted the innovation (Rogers, 2003). For example, 
a grower may talk to a neighbor who has previously implemented a new technology to find out more about the product in practice. A good or bad review will influence rate of adoption. We suggest that extension educators also facilitate this communication by providing both objective and subjective evaluations of technologies that are disseminated through localized, agricultural social systems. In addition, extension both reacts to and produces trialability and observability within the social system.

Social systems are composed of individuals, informal groups, and/or organizations, bound together by common problems and mutual goals (Rogers, 2003). Entities can belong to multiple social systems. For example, an emerging farmer may belong to a geographically based, crop-specific social system as well as a new farmer social system. Each social system may have different problems or goals. These social systems are important because "diffusion occurs within a social system" (Rogers, 2003). For this project, participants mainly discuss their regional fruit-growing social systems with extension as one node in the system.

It is apparent that participants engage with multiple social systems. For example, many Pennsylvania participants sell at farmers markets in urban areas, including Baltimore, $\mathrm{MD}$, and Washington, DC. This engagement with an urban audience influences the assessment of problems, goals, and decision-making. Although the position of individuals in multiple social systems will not be discussed in this article, it is important to recognize that entities are not bound by one social system and may be facilitators or gatekeepers of the diffusion of innovations from one social system to another.

The Smith-Lever Act of 1914 established state agricultural extension services with the explicit goal of "aid[ing] in diffusing among the people of the United States useful and practical information on subjects relating to agriculture and home economics, and to encourage application of the same" (as cited by Rogers, 2003). Accordingly, the goal of extension is to actively participate in the diffusion of both intellectual and technological innovations. The CASC project and this research considered these goals in looking at how extension might move knowledge and technology along the network of their social structure, bridging the public, commercial interests, and academia.

\section{Results and discussion}

Participants were generally comfortable with the idea of technological innovation, with one succinctly saying that "you've gotta move forward. If you're not moving forward, you're moving backwards, and people who think they can just continue to do what they did before, it's not happening." However, participant perspectives regarding these three technologies varied, as discussed below. We have included direct quotations from participants in this article to maintain the integrity of their opinions and statements. It should be understood that these quotations come from semistructured verbal interviews and have not been altered for grammatical correctness.

Harvest-assist techNology: Benefits of adoption. Because the participants emphasize fresh marketing rather than processing, the effect of harvest-assist technology on fruit quality was brought up repeatedly. For example, Pennsylvania growers focus on direct marketing, especially farmers markets, thus high quality is of utmost importance, as represented by this statement by one participant: "If there really is a noticeable increase in quality with the use of harvest-assist technology, that's gonna have to be a consideration in our willingness to adopt it because that...I mean, that at this point should be the cornerstone of anything someone is trying to do on the East Coast is maintaining a more rigid standard of quality." Not all participants were confident that harvestassist technology would increase quality, but most felt that achieving comparable quality to their present practices would be acceptable.

Other growers pointed out the positive benefit of reducing human error and fatigue during harvest: "I think the efficiency of it and having all of the workers there and not having to carry a ladder, well hopefully if they are just on a platform of some sort like that, not carrying ladders, not carrying picking bags, the stress on them that throughout the day tires them out wouldn't be there. They could continue to pick. I think that would probably be the biggest benefit." Many participants discussed the influence of the labor force on their prospective adoption of any type of mechanized harvest. Although quality appears to be the most important factor, the role of laborers is also part of the decision-making process.

Reflecting on the economic importance of labor, one participant explained the potential impact of the harvest assist on the labor force as follows: "Labor is about $50 \%$ of our total cost of operation and that we're a high cost operation and so anything that we can do to make that labor bill go down, and we don't mind putting some capital after that, as long as we're sure that we can utilize the capital every year. Okay, so your risk goes up when you have a huge amount of capital. If you freeze out, your capital cost stays there for a year, even though you don't get to use it. If you freeze out, you send your workers home and so you don't send your piece of equipment home, you have to pay for it in that year. But that aside, I still think that since $50 \%$ of our cost is labor, anything we can do to decrease that labor bill is something we have to do." Research has shown that labor during harvest generally accounts for $14 \%$ to $53 \%$ of variable costs in apple (Malus domestica) and cherry (Prunus avium) production (Galinato et al., 2009; Gallardo et al., 2009), thus this participant's labor costs are consistent with the industry.

The possibility of a labor shortage was also on the minds of several participants, with one saying that a push for mechanical assistance to harvesting was to "stave off the impending lack of labor." Another participant described the risk associated with the current labor pool as follows: "I mean, we're doing it for efficiency and the fact that we just frankly think...take efficiency out of it, it's if you're gonna get your crop harvested, we're not gonna have the people there. So we gotta reduce our dependence on this labor force." Most participants who discussed their laborers seemed to view changes in the labor pool as inevitable. Research has shown a sharp downward trend in net migration between the United States and Mexico beginning 5 years ago, with net migration now at zero and data suggest future net outmigration from the United States. (Passel et al., 2012).

HARVEST-ASSIST TECHNOLOGY: Barriers to ADOPTION. Participants addressed many challenges to the 
potential adoption of the harvest-assist technology. One participant summed up concerns over cost as "you can have a great thing that does not bruise a single apple, makes your workers terribly efficient, but you can't afford to buy it because that's the three-legged stool that we have is how much capital is required to run the operation." In addition to financial cost, participants were concerned about geographic limitations, the pitfalls of technology, and the management of workers.

Pennsylvania growers were especially concerned about the impact of land use and land topography on the viability of using this technology. Several growers indicated that they have multiple parcels of land and would be concerned about movement of the machine from one to another, or the cost of multiple machines, especially because their overall acreage is relatively small. Furthermore, participants are concerned by hilly terrain with muddy land parcels, as one study participant described: "We have a lot of ground with apple trees on it that you could never take those vehicles. Some of the ground, if it were developed and tweaked in the right way with automatic leveling and so forth, you probably could, but we have some ground that you will never take one of those vehicles. It's dangerous to be on them with a tractor for somebody that has driven a tractor their entire life. Here, for us to consider the adoption of one of those technologies, it's going to have to either provide a large enough benefit on enough acres on our ground, real ground that we have, not hypothetical flat ground, but real ground that we own, it has to provide enough benefit or there have to be enough jobs that it can perform on those same acres that I can now spread out instead of not just being a harvest-assist technology, you know." One Washington grower shared similar concerns over movement of machinery, comparing it to moving people: "And on our farm, to get from that end to that end, it's over a mile to get from one end to the other, even though they are contiguous acres. So I would definitely concur with those fears and, if I have a slow-moving platform and it's down there and I have a crew of people that needs to go from this 'Honeycrisp' orchard to that 'Honeycrisp' orchard up there, I can get them there on a bus real quick, but how's this get from there to there."

Several participants indicated the potential problems associated with machines and maintenance. These concerns were primarily about the long-term reliability of the technology. One participant indicated that "The other big downfall is that it's machinery. It is equipment. It will break. And they always break at a critical time. Well when you're in harvest, every day is a critical time. So it will be very dependent upon somebody being able to service it and keep it running all the time." Similarly, another participant questioned how the complexity of the technology would influence repairs: "When you have a breakdown so to speak, how quickly can it be repaired, where do you go to get the information to get things repaired? That all has to be brought into...you know, can Joe who has been trained to operate the machine, if something breaks down, can he fix it? Do we have to have tech support whom Joe does not really understand or comprehend the terminology? That would be a big, I don't want to say a hindrance, but it would be something we would have to think about." Availability to service and purchase parts has been a limiting factor for the adoption of other technologies as well (Washington State University, 2010).

Although many participants discussed how they are changing their planting systems, the proportion of land that has transitioned and would be appropriate for this technology is of concern. One participant discussed the potential limitation as follows: "As our farm is currently planted, there would be in terms of what's in the ground, there would be one, two, three, maybe a total of four or five blocks out of the whole apple operation that would be a best fit for this technology, and that's out of like 30, 40 , whatever. So as we keep re-planting in a similar fashion, you know as we continue to re-plant apples, if those blocks continue to take on the same high-density narrow canopy dimensions as the four blocks we're talking about, that would increase the likelihood that we would adopt the technology."

Implementation of this style of harvesting will change the dynamics of many operations. This led one participant to say that "Really, it boils down to just management of the people, that's gonna be the biggest hurdle." Many participants indicated they currently pay their laborers by the piece (i.e., per bucket or unit harvested). Using harvest-assist technology would inhibit tracking individual pieces, and participants indicated this could cause problems when workers accustomed to picking by the piece do not want to be paid by the hour or work in teams.

EleCtRonic INSECT TRAP BENEFITS. The majority of participants were interested in the increased accuracy of electronic insect traps. Many participants indicated a desire to be early testers or adopters. Consistency and reliability of information about pests were potential benefits commonly mentioned by participants: "I mean, it's good to know what pests are out there. What we often wonder when we go check traps is how accurate is it really and we're human beings, so if someone forgets one day maybe or a week someone forgets to check them or someone is on vacation, the person that's supposed to be checking them. So yeah, computers don't go on vacation. But it is an advantage that it may be more accurate data." Many participants knew the developers of this technology, and this seemed to influence their trust in the technology: "Fortunately it's being run by individuals in whom we have a lot of faith and trust, you know. And Larry, there isn't anybody that I would trust more than him when it comes to developing that. And Larry speaks incredibly highly of Johnny Park and what his part is in it, so I'm pretty confident that they're gonna develop something and when they says it's ready to go, it's gonna be ready to go because Larry won't say so otherwise."

Some participants saw the possibility that these traps could lower their operation costs. Many larger operations used spray consultants for trap monitoring. Two participants described potential benefits as "[Checking traps] takes a half a day. I mean, I'm not doing it. My spray consultant is doing it, but I would like him not to have to do it either. If I didn't have to have somebody checking my traps, then why would I need a spray consultant? Then I could shop a little more for chemicals, maybe. So I indirectly see the cost of running 
that monitoring program because it's part of the cost that the spray company has to endure and has to tack on to my spray bill. My spray bill is probably, after labor it's my second biggest cost."

Electronic INSECT TRAP BARRIERs. Not all participants were convinced that this technology would be useful. The potential cost savings were questioned by several participants, especially those who do not feel they currently devote much labor time to trap monitoring. One explicitly critiqued the project, stating that it is not cost-effective. In addition, checking of traps can coincide with other labor activities. One participant pointed out how the person currently checking traps simultaneously checks fruit: "I guess one of the drawbacks to it is she really looks at the fruit when she's in the orchard, so she does get to look at it and, if someone else is spraying for me, which happens on a regular basis, I am not in the orchard to actually see what's going on. And she does a lot of looking at what's going on in the orchard. So that would be one drawback, not having a person that sort of knows what to look for in the orchard. But whoever's doing the spraying needs to be trained also to know what they're looking for. So that would be minor on I guess my part."

Some participants questioned the handling of data gathered from the traps, with one describing hypothetical concerns as follows: "We've been a remarkably open industry in sharing information and so having all of the sudden the prospect of having either weather systems or whatever collect huge amounts of data and then have it be proprietary information, all of the sudden then people are saying well, you know, if it's going to be proprietary, I'm not sure that I really want my information included in there. And then that wrecks the whole thing, you know." This sentiment was complemented by another participant's comment that "The other problem you get into is you want to get your neighbor to buy them. And hopefully his orchard's indicative of what's going on in your orchard." However, most participants did not express such concerns.

ON-THE-FLY COUNTER AND CALIPER: BENEFITS OF ADOPTION. Nursery participants varied greatly in marketing strategy and counter and caliper needs. Accordingly, participants had varying reactions to the on-the-fly counter and caliper.

Although not consistent across all participants, some participants were optimistic that technology would be more accurate than human counting due to human error. As one participant noted, "Different people count differently." One participant also thought this compilation of data could positively affect the market potential of their plants: "What the technology would allow us to do is have access to information much earlier in the process by a minimum of 2 weeks and realistically probably 6 weeks, and that means that the person who is responsible for putting together orders and shipping those orders could do so with much greater confidence and that would allow us to ship product earlier which opens up new market areas for us."

ON-THE-FLY COUNTER AND CALIPER: BARRIERS TO ADOPTION. Participant concerns over the feasibility of this technology, focused primarily on environmental concerns and the type of information obtained when measuring. The following quotation summarizes concerns expressed by several participants regarding the environment: "Durability and ruggedness and weatherproofing are other concerns, and just ability to operate even in good weather. You know, we have dust and other elements that are challenging to any optical system. So I think we have a lot of work to do with more rigorous field testing."

Several participants indicated that human interaction is central to caliper measurements, thereby critiquing the applicability of this technology in their operations. One grower commented: "Yeah, you want some labor shift, but again when it comes back to the calipering, I think there's a lot of human eye interaction to that plant that may not be accounted for in the computer." Another grower asked, "The caliper's only a portion, maybe a fourth of what you guys are really doing when you guys do final sizing? A third grower commented: "The caliper thing, I gotta tell you, that's gonna be just a big challenge because there's a lot of variability. I think, you know if you were looking at just preliminary, just really basic information, the technology probably could fit into it, but to the detail that we need to go in, I think it's gonna be a challenge."
LESSONS, IMPLICATIONS, AND SUGGESTIONS FOR FUTURE WORK. In two of the three study locations, university extension personnel were present during interviews. For some participants, these interviews were their first exposure to the technologies, thus it was appropriate to have access to expertise. However, this also may have influenced the participants' responses to some questions. For example, the harvest-assist technology was still in a testing phase of development, and known current problems were sometimes included during the descriptive process. Such a description may have biased participants toward a more critical assessment of barriers to implementation.

Also, when asked about sources of information regarding new technologies, the presence of extension personnel may have influenced a respondent to either indicate them first or not at all (or at times, only after probing). Accordingly, it is not feasible to discuss the degree of influence extension offices and personnel have in diffusion of technology. Similarly, the sampling bias of recruiting participants through extension must be recognized. We can justify such bias due to the potential test market of the developing technologies, but previously discussed themes should not be considered generalizable to the entire production fruit tree or ornamental and fruit tree nursery sectors.

Future research could explore the position of extension personnel in diffusing information. Social network analysis, a quantitatively derived representation of relationships, may be one method to explore the current effectiveness of extension personnel as transmitters of knowledge (Wasserman and Faust, 1994). Conversations between the interviewer and extension personnel also showcased different perceptions on technology and the role of extension in disseminating information on technology. If extension educators desire to increase the rate of diffusion, it may be useful to research the long-term effectiveness of different approaches. Similarly, a diffusion of innovations approach could be used in evaluating extension program impacts (Hubbard and Sandmann, 2007). In addition, research could explore how extension influences the social structure of a social system (Rogers, 2003).

Our research results suggested a positive relationship between anticipated 
implementation of technology and knowledge of and trust in designers of that technology. Diffusion of innovation suggests that the ability to try out and/or observe an innovation will increase its adoption rate (Rogers, 2003). Future research could explore how varying levels of exposure to technology influence verbal interest in that technology (and perhaps also actual purchasing of technology). For example, many of the Washington production grower participants had not had personal exposure to the harvest-assist technology. Research time constraints inhibited conducting interviews after the "field day" activity that would have provided such exposure. Conversely, most of the Pennsylvania participants had previous knowledge of and exposure to the electronic insect trap.

During the interview process, it became apparent that different business strategies, including marketing strategies and use of consultants, influenced responses. Marketing strategy may have been a more important variable than acreage, and future research may find stratification by direct marketing or distribution more prudent. In retrospect, talking to many of the Washington growers about insect pest management technology likely was not the appropriate audience. Instead, the target audience for this product, in this location, is likely chemical distributors and their chemical consultants. Pennsylvania growers, on the other hand, typically handled monitoring of insect traps internally and their responses reflect this involvement.

Some participant responses alluded to a lack of a clear idea of daily operations and needs during the design process of technology. This can be most clearly seen in the nursery grower interviews on the counter and caliper. For some participants, counting and diameter measurements were done in conjunction with other tasks, including confirmation of species and checking the health of the tree. Such tasks cannot currently be automated, thus these participants did not consider the technology pragmatic. In contrast, one nursery grower who was particularly enthusiastic about the counter and caliper has a different business model and different needs. It is important to note that the sampling of nursery participants is too low for any clear consensus, but future research could stratify across different business models, especially plant growth stage and intended product buyers to explore marketability and relevance.

Strengthening trust in the designer and a designer's knowledge of technological needs in practice could be fostered through greater involvement of growers in the concept and design process of technology development. The degree of needed participation may vary depending on the level of innovation. For example, the electronic trap is a recognizable product, working with a well-established concept of pest management, but collects and distributes information without the need for a physical body. Accordingly, potential adopters may not need to participate much in concept and design. For nonradical innovations, it may be prudent to question potential adopters how price will impact decisions on adoption over more traditional forms before design and production.

\section{Literature cited}

Adrian, A.M., S.H. Norwood, and P.L. Mask. 2005. Producers' perceptions and attitudes toward precision agriculture technologies. Comput. Electron. Agr. 48:256-271.

Alston, J.M., G.W. Norton, and P.G. Pardey. 1995. Science under scarcity: Principles and practice for agricultural research evaluation and priority setting. Cornell Univ. Press, Ithaca, NY.

Baugher, T.A., J. Schupp, K. Ellis, J. Remcheck, E. Winzeler, R. Duncan, S Johnson, K. Lewis, G. Reighard, G. Henderson, M. Norton, A. Dhaddey, and P. Heinemann. 2010. String blossom thinner designed for variable tree forms increases crop load management efficiency in trials in four United States peach-growing regions. HortTechnology $20: 409-414$.

Bernard, H.R. 2005. Research methods in anthropology. 4th ed. Altamira Press, London, UK

Ellis, K., T.A. Baugher, and K. Lewis. 2010. Results from survey instruments used to assess technology adoption for tree fruit production. HortTechnology 20:1043-1048.

Galinato, S., R.K. Gallardo, and M. Taylor. 2009. Cost estimates of establishing and producing sweet cherries in Washington. Washington State Univ. Ext. Factsheet FS022E.

Gallardo, R.K., M. Taylor, and H. Hinman. 2009. Cost estimates of establishing and producing Gala apples in Washington. Washington State Univ. Ext. Factsheet FS005E.
Gibbs, G. 2002. Qualitative data analysis: Explorations with NVivo. Open Univ. Press, London, UK.

Hammersley, M. and P. Atkinson. 1995. Ethnography: Principles in practice. Routledge, London, UK.

Hubbard, W.G. and L.R. Sandmann. 2007. Using diffusion of innovation concepts for improved evaluation. J. Ext. 45(5). 2 Dec. 2013. <http://www. joe.org/joe/2007october/al.php>.

Kitchen, N.R. 2008. Emerging technologies for real-time and integrated agriculture decisions. Comput. Electron. Agr. 61:1-3.

Koundouri, P., C. Nauges, and V. Tzouvelekas. 2006. Technology adoption under production uncertainty: Theory and application to irrigation technology. Amer. J. Agr. Econ. 88:657-670.

Lamb, D.W., P. Frazier, and P. Adams. 2008. Improving pathways to adoption: Putting the right P's in precision agriculture. Comput. Electron. Agr. 61:4-9.

Llewellyn, R.S. 2007. Information quality and effectiveness for more rapid adoption decisions by farmers. Field Crops Res. 104:148-156.

Miles, M.B. and A.M. Huberman. 1994. Qualitative data analysis: an expanded sourcebook. 2nd ed. Sage Publications, Thousand Oaks, CA

Passel, J., D. Cohn, and A. GonzalezBarrera. 2012. Net migration from Mexico falls to zero - and perhaps less. Pew Hispanic Ctr., Pew Res. Ctr., Washington, DC.

Reichardt, M. and C. Jürgens. 2009. Adoption and future perspective of precision farming in Germany: Results of several surveys among different agricultural target groups. Precis. Agr. 10:73-94.

Rogers, E.M. 2003. Diffusion of innovations. 5th ed. Free Press, New York, NY.

Sassenrath, G.F., P. Heilman, E. Luschei, G.L. Bennett, G. Fitzgerald, P. Klesius, W. Tracy, J.R. Williford, and P.V. Zimba. 2008. Technology, complexity and change in agricultural production systems. Renewable Agr. Food Systems 23:285-295.

Washington State University. 2010. A road map to improve chemical delivery technologies in specialty crops. 21 Nov. 2013. <http://wine.wsu.edu/researchextension/files/2012/01/Road-Map_ MASTER_V3.pdf>.

Wasserman, S. and K. Faust. 1994. Social network analysis: Methods and applications. Cambridge Univ. Press, Cambridge, UK.

Wejnert, B. 2002. Integrating models of diffusion of innovations: A conceptual framework. Annu. Rev. Sociol. 28:297-326. 